the successful issue of the case chiefly to the antitetanic serum.

H. R. T., male, aged 30 , fell on the evening of January 12 th last, and struck the bridge of the nose against the kerb of the pavement, causing an abrasion, after which the face is said to have become greatly swollen. He first sought advice on January 27th, complaining of an uncontrollable impulse to laugh, and of a "drawn" sensation of the left side of the face since the 25th. He had laughed, quite against his will, on the receipt of the news of the death of a relative. No limitation of the movements of the jaw could be made out, nor any objective symptom. The abrasion had healed. When next seen on the evening of Sunday, January soth, $^{\circ}$ eighteen days after the injury, there was slight but distinct trismus, slight ptosis of the left eye, and inability to close the eyelids completely some right facial paralysis, and a painful feeling of stiffness

waist. No cramps nor stiffness of the neck were complained of. January 3rst. Symptoms somewhat more marked; some difficulty in swallowing; slight wrinkling of forehead; a few cramps in legs; towards evening the neck became stiff; ro c.cm. of antitoxin injected. A full dose could not be given, as through a misunderstanding only a prophylactic

February rst. Slept well. Trismus increased, and body become stiff: towards evening back of neck became quite rigid; $60 \mathrm{c.cm}$. of antitoxin injected.

February and. Slept well, except for a few spasms of a not very severe became rigid, and there was distinct opisthotonos.

cone rigid, and there was distinct opisthotonos. February 3 rd. Sleep more disturbed ; spasms more frequent and severe, the tongue being frequently bitten. Opisthotonos well marked, but the legs being unaffected, the arch was between the buttocks and the occiput. Teeth firmly clenched; fed by siphoning liquids from a baby's feeding bottle, the india-rubber tube being attached to a straw which was insinu-
ated through the gap in the teeth in which he held his pipe. Spasms ated through the gap in the teeth in which he held his pipe. Spasms frequent throughout the day; patient in a very despondent state. In the hydrate gr. $\mathbf{x v}$ with sod. brom. $\$ j$ ordered to be given every four hours. By night there was slight relaxation of the trismus, and the spasms were noticed to be less frequent.

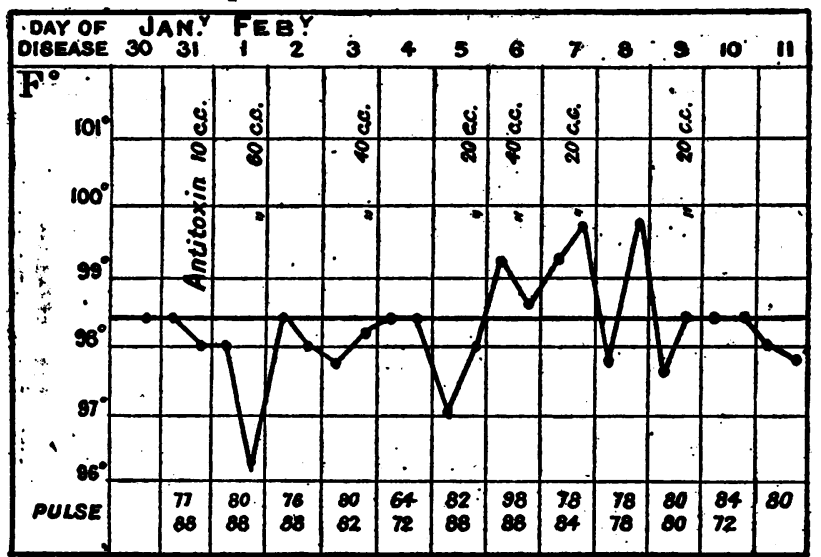

February th. Slept eight hours : abdomen and back less rigid. Patient in much better spirits; head can be moved slightly forwards; facial paralysis less marked. Fewer spasms (twenty-five in twelve hours)

February 5 th. Trismus again more intense. Spasms fewer (nine in twelve hours), some severe, tongue being frequently bitten; 20 c.cm. of antitoxin injected. It was hoped to inject more, but Messrs. Burroughs and Wellcome's supply was exhausted on that day. One hour after injection the trismus relaxed sufficiently to admit the little finger as far as the middle joint

February 6th. Slept well first part of night, but had frequent and sharp spasms from 4 A.M. till 8 A.M. Teeth could be separated 1 inch. Fifteen spasms during day; $40 \mathrm{c.cm}$. of antitoxin injected at 2 P.M. Abdomen in the evening less rigid, and opisthotonos less marked. Hypodermic injection of gr. of morphine with gers. of atropine at night.

February 7 th Slept seven hours in night with only two spasms. Spasm February 7 th. Slept seven hours thotonos quite slight, but abdomen not greatly relaxed. Teeth could be separated sufficiently to allow patient to drink from a cup. Five spasms during the dag $20 \mathrm{~cm}$ of antitoxin injected.

February 8th 'Three spasms only throughout the day; very drowsy. Chloral mixture discontinued ; catarrhal conjunctivitis of both eyes.

February gth. No spasms; opisthotonos disappeared movements of head free; 9 .

February roth. No spasms; able to eat minced chicken and mashed potatoes.

February rith. Slept well, no spasms. Neck and back quite supple. still some rigidity of abdomen, and trismus. Ptosis of left eye persists,

and a slight degree of right facial paralysis. movements of the jaw are not yet absolutely free.

February rgth. All trace of trismus and rigidity of the jaw gone; facial paralysis and ptosis disappeared : able to walk about well.

On March 5 th the patient went to the seaside, and on the 2rst was able to return to work.

It is interesting to note the presence of ptosis, which is said to be very rare in cephalic tetanus, and the emotional disturbance accompanying the onset. Altogether $210 \mathrm{c.cm}$. of serum were injected. The injections were made into the cellular tissue of the back by one or more punctures, $20 \mathrm{c.cm}$. being injected at each puncture. The usual antiseptic precautions were observed, no inflammation occurred, and but little pain was caused. The serum was obtained through Messrs. Burroughs and Wellcome from the Pasteur Institute at Paris.

$$
1 \text { Diseases of the Nervous System, vol. ii, p. 63r. }
$$

\section{A CASE OF TRAUMATIC TETANUS TREATED WITH ANTITOXIN.}

By G. BLACKER MORGAN, JuN., M.B., Sunderland.

H. M., aged 20, a farmer, was kicked over the right eye by a young unshod horse. A lacerated wound below and parallel to the right eyebrow was thus produced. The wound was seen some twelve hours later and thoroughly cleansed with carbolic lotion, and two sutures of carbolised horsehair put in. By the sixth day the wound was quite healed and the œdema of the eyelid had disappeared. On the seventh day he complained of some stiffiness of the jaw. There was puffiness of the right side of the face simulating facial paralysis. On the morning of the eighth day, after a very restless night, he developed the typical sardonic smile, with tonic spasm of the muscles of the face and neck. He was given chloral hydrate $20 \mathrm{gr}$. every two hours, and was kept in bed in a darkened room; he was very restless all day, and had increasing difficulty in swallowing. Injected $8 \mathrm{c.cm}$. of antitoxic serum into the abdominal wall at 6 P.M. The temperature was $97.6^{\circ} \mathrm{F}$., and the pulse 56 . He was also given an enema of potassium bromide $3 \mathrm{ss}$ and chloral $25 \mathrm{gr}$., in milk $\xi$ iv, and this was directed to be repeated every two hours. At I0.30 P.M. it was reported that he had been quieter. There was no reaction from the antitoxin, and the temperature was still subnormal, pulse 60 . He had a restless night, but slept some three hours. On the ninth day there was very little twitching, and grinding of the teeth occurred twice. He retained all the enemata but one, and took an ounce and a half of milk by mouth. The temperature was $98.4^{\circ}$, and the pulse 62 . Injected 8 c.cm. of antitoxin at II A.M., passed a catheter and emptied the bladder, drawing off a copious secretion loaded with phosphates. At 6.30 P.M. the third injection of antitoxin, 8 c.cm., was given, and the bladder emptied. He did not retain the enemas. The temperature was $99.6^{\circ} \mathrm{F}$. At II.P.M. the spasms were very frequent and opisthotonos well marked. Gave him a hypodermic injection of chloral, gr.10, and restrained the spasms with chloroform.

On the tenth day, at 6.30 A.M., after a quiet night, he was: much more conscious and answered distinctly. He was given another hypodermic injection of chloral during the night (gr. Io). At I.30 P.M. found he had got steadily worse since the early morning, and was quite unconscious; the conjunctivæ were insensitive, and tetanic spasms were nearly continuous, but could be controlled by chloroform. The pulse was 100, and the temperature $99.8^{\circ} \mathrm{F}$. At 3 P.M. repeated the hypodermic injection of chloral (gr.10), and at 4 P.M. he was quieter. At I I P.M. the pulse was 120, and the temperature $102^{\circ}$ F. Cheyne-Stokes respiration was observed. Injected $16 \mathrm{c.cm}$. of antitoxin, and emptied the bladder with a catheter. He died at 2.30 A.M. on the eleventh day.

Remarks. - The colt which caused the injury was kept in a loose box in which a horse had died from tetanus three months previously. The loose box had not been disinfected in any way. The wound healed quite normally, and on the sixth day all swelling had subsided. The eyelid became swollen again on the ninth day, but there was no fluctuation to be made out over the wound. He had three injections of antitoxin, $8 \mathrm{c.cm}$. in each, in the first twenty-four hours, but, owing to the difficulty in cbtaining a further supply, there was a delay of twenty-four hours before the fourth injection of $16 \mathrm{c.cm}$. could be administered. It is possible that the general improvement in his condition in the early morning of the tenth day might have been maintained had there been a further supply of antitoxin at hand. The injections caused no local disturbance nor pain. 